\title{
REMARKABLE EFFECT OF TOPICAL BETAMETHASONE VALERATE 0.1\% ON PROGRESS OF PSORIASIS DISEASE.
}

1. MBBS, MPhil, PhD,

Associate Professor

Department of Pharmacology

Jinnah Sindh Medical University,

Karachi

2. MBBS, MPhil

Associate Professor

Department of Pharmacology

Dow University Health Sciences,

Karachi

3. MBBS, M.Phil

Senior Instructor

Biological and Biomedical Sciences AKU

Correspondence Address:

Dr. Farah Asad

Department of Pharmacology

Jinnah Sindh Medical University,

Karachi.

asad-farah@hotmail.com

Article received on:

18/07/2018

Accepted for publication:

22/01/2019

Received after proof reading:

$28 / 08 / 2019$

\author{
Farah Asad', Fatima Rizvi², Arfa Azhar ${ }^{3}$
}

ABSTRACT... Psoriasis is immuno-inflammatory condition devouring huge negative impact on patient's life as compare to other diseases. Topical regimen is the standard treatment for mild to moderate psoriasis disease. The data of effectiveness of Betamethasone Valerate $0.1 \%$ on large number of psoriatic patients were being deficient. Objectives: This study evaluates the Topical Betamethasone Valerate $0.1 \%$ impact on patient's life in relation to efficacy and safety. Design: Interventional experimental study. Setting: Study was carried out Basic medical sciences institute (BMSI) alliance with Dermatology Department JPMC, Karachi. Period: June 2013 to June 2016. Methods: 75 chronic plaque type psoriatic patients prescribed Betamethasone Valerate $(0.1 \%)$ topically along with placebo for 6 months once daily (one week interval after three week application). The therapeutic effectiveness and safety of studied drug were assessed by means of PASI, DLQI and hsCRP. The results analyzed by using repeated ANOVA. Results: Results revealed when camparasion of all parametres with base line they were significantly reduced as mean percentage change were $75.001 \pm 0.0563,72.215 \pm 3.17$ and $33.692 \pm 7.980$ for PASI, DLQI and hsCRP respectively at the end of study. Safety profile of therapy showed non-significant outcomes. Conclusion: Betamethasone valerate $0.1 \%$ is better treatment option in mild to moderate psoriatic patients to improve quality of life and decrease disease severity.

Key words: $\quad$ Betamethasone Valerate $0.1 \%$, hsCRP, Psoriasis Vulgaris, PASI, Quality of Life.

Article Citation: Asad F, Rizvi F, Azhar A. Remarkable effect of topical betamethasone valerate $0.1 \%$ on progress of psoriasis disease. Professional Med J 2019; 26(9):1542-1545. DOI: 10.29309/TPMJ/2019.26.09.4020

\section{INTRODUCTION}

Psoriasis is an autoimmune disorder associated with several systemic co-morbidities. Hence inflammation is a prime factor for many autoimmune diseases. Therefore primary aim of therapy against psoriasis would to decrease progression of disease and thus improving both local dermal lesions and also associated systemic co-morbidity. Therefor improvement the study of health related quality of life in psoriatic patients regimen against psoriasis should cover both local skin inflammation and associated systemic spillovers of inflammatory mediators.

Unfortunately there is no ideal remedy for psoriasis that magnificently improving both primary skin lesions and associated co-morbidities. Numerous accessible medications of psoriasis can assist just with controlling skin lesion and associated symptoms. ${ }^{1}$ Among all available treatment options for psoriasis only topical steroids remains gains superiority for management of all stages of psoriasis either as sole or as combinatory regimens..$^{2,3}$

Therefore nowadays about $80 \%$ of psoriatic patients were treated topical steroids efficaciously. ${ }^{4}$ Because Corticosteroids able to reducing the cellular inflammation without adversely affecting. ${ }^{5}$ Correspondingly Corticosteroids would able to inhibit synthesis of local inflammatory mediators and thereby their systemic spill over specially cytokines and prostaglandins (IL-6 and 8, TNF-a, Interferon- $\gamma$, leukotrienes). Similarly steroids able to decrease abnormal CD4:CD8 ratio and also decreases the numbers and retard the hyperstimulation of Langerhans cells. ${ }^{6,7,8}$

The severity of psoriasis disease in clinical trial assess by PASI Scoring which is most commonly used reliable parameter to evaluate the disease 
progress. PASI explained the lesion via redness, thickness and scaliness. Most of the researchers used this variable for the assessment of newer drug's effects on the progress of psoriasis disease severity. ${ }^{9}$

Cardiovascular manifestations were most prevalent systemic complication associated with psoriasis. ${ }^{10}$ Hence systemic complication in psoriasis mostly due to systemic inflammation and CRP is the imperative predictive marker for both severity of psoriasis and its systemic manifestations. ${ }^{11}$

\section{MATERIALS AND METHODS}

Seventy five psoriatic patients enrolled in this study, 09 patients were lost from follow-ups. Patients were prescribed local application of Betamethasone Valerate $0.1 \%$ once time in a day with placebo for six months.

\section{Inclusion Criteria}

Were includes both gender of age 25-65 years with PASI scoring of $<12$ and hsCRP is $\geq 3$.

\section{Exclusion Criteria}

Were includes those patients having Steroid and Statin treatment in past one month or history of pregnancy, lactation and others chronic illness. Study period was 180 days and approved by JPMC Ethical Committee. The effectiveness of study drug assessed by Psoriasis Area and Severity Index (PASI). This index explained the treatment effectiveness by change in PASI i.e. 50\%, 75\% and $90 \%$.Clinically those drug are effective which shows $50 \%$ of change as approved by FDA. A PASI score of $>12$ means disease is severe, 7-12 score is moderate and $<7$ is mild. ${ }^{12}$ C-reactive protein is directly related to inflammation and it rises in psoriasis. Measuring CRP level can be used as a key predictive factor to response the treatment. ${ }^{13}$ Patient's quality of life was estimated by Dermatological Life Quality Index (DLQI) before and end of the therapy. ${ }^{14}$

\section{STATICAL ANALYSIS}

Statistical analysis was done by using SPPP ver. 16.0 and for clinical effectiveness of studied drug statistical method repeated measure ANOVA was applied. Only $p$ values $<0.05$ and $<0.001$ were reflected as statistically significant and highly significant respectively.

\section{RESULTS}

Results of demographic data revealed that most of the middle aged patients with positive family history, smoking history and disturbed sleep. Most of them had moderate type lesion and located on upper limb and lower limb as depicted in Table-I. The outcome of all clinical parameters associated with psoriasis as compare to baseline of studied drug showed statistically significant improvement at the end of study such as mean PASI $2.806 \pm 0.183$ ( $p$ value $=0.0001)$, mean hsCRP2.65 \pm 0.40 ( $p$ value $=0.0001)$ and mean DLQI $5.55 \pm 0.53(p$ value $=$ 0.001 ) with significant percentage change most of them reached PASI 50 as depicted in Table-II. Patients showed mild to moderate type of adverse effects like skin manifestations (rash, burning and redness) as showing in Figure-1.

\begin{tabular}{|l|l|}
\hline \multicolumn{2}{|c|}{ Demographic Data } \\
\hline $\begin{array}{l}\text { Age: } \\
\text { Gender: }\end{array}$ & $46.52 \pm 7.84$ \\
Male: & $57(86.37)$ \\
Female: & $9(13.64)$ \\
Family History: & $36(54.50)$ \\
History of Smoking: & $42(63.64)$ \\
Sleep Disturbed: & $66(100)$ \\
Mild-PASI: & $1(1.51)$ \\
Moderate PASI: & $65(98.49)$ \\
Disease Duration (Months): & $5.65 \pm 2.18$ \\
\hline \multicolumn{2}{|c|}{ Location of Lesions } \\
\hline Head: & $34(51.51)$ \\
Upper Limb: & $63(95.45)$ \\
Lower Limb \& Groin: & $62(93.93)$ \\
Trunk: & $56(84.84)$ \\
Nails: & $0(0)$ \\
\multicolumn{2}{|c|}{ Table-l: Demographic Data } \\
\hline
\end{tabular}

Adverse Events in Patients

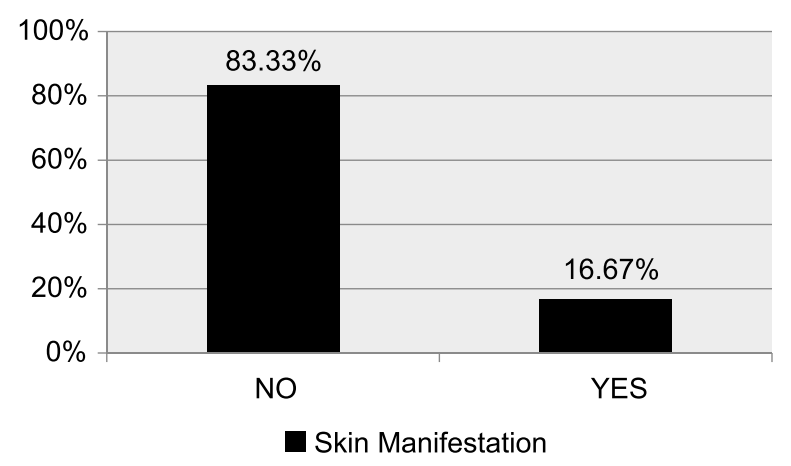

Figure .1 


\begin{tabular}{|l|c|c|c|c|}
\hline Outcome Variables & Baseline & $\begin{array}{c}\text { Three Months } \\
\text { Follow-up }\end{array}$ & $\begin{array}{c}\text { Six Months } \\
\text { Follow-up }\end{array}$ & P-value \\
\hline $\begin{array}{l}\text { Psoriasis Area and } \\
\begin{array}{l}\text { Severity Index (PASI) } \\
\text { (Percentage Change) }\end{array}\end{array}$ & $11.277 \pm 0.729$ & $\begin{array}{c}3.910 \pm 0.272 \\
(65.176 \pm 0.424)\end{array}$ & $\begin{array}{c}2.806 \pm 0.183 \\
(75.001 \pm 0.0563)\end{array}$ & 0.0001 \\
\hline $\begin{array}{l}\text { hsCRP } \\
\text { (Percentage Change) }\end{array}$ & $4.00 \pm 0.31$ & $\begin{array}{c}3.37 \pm 0.41 \\
(15.767 \pm 5.67)\end{array}$ & $\begin{array}{c}2.65 \pm 0.40 \\
(33.692 \pm 7.980)\end{array}$ & $0.0001)$ \\
\hline $\begin{array}{l}\text { Dermatological Life } \\
\text { Quality Index (DLQI) }\end{array}$ & $20.2 \pm 1.16$ & - & $5.55 \pm 0.53$ & $(0.0001)$ \\
\hline \begin{tabular}{l} 
Percentage Change) \\
\hline
\end{tabular} & & & $(72.215 \pm 3.17)$ & 0.0001 \\
\hline
\end{tabular}

Table-II: Comparison of Outcome Variables (Psoriasis Area and Severity Index, hsC-Reactive Protein, Dermatological Life Quality Index) among Patients at Baseline and Follow-ups

\section{DISCUSSION}

Betamethasone is a powerful anti-inflammatory and immuno-modulatory agent. ${ }^{15}$ Apart from that it also had anti proliferating effect that would worthful for condition they had duel hperproliferative and immunological consequences ${ }^{16}$ In this study we found the commonest site of lesions were upper limb and lower limb with the history of itching, smoking and positive family history. Most of the patients reached PASI 50 at the end of the study and one patient at PASI $75 .{ }^{17}$ Hence Psoriasis is associated with immune induced inflammation so steroids would valuable treatment option for this condition. Psoriasis produced negative psychological and social effect on life and health of patients. So DLQI is used for measurement in term of patient's quality of life but also effectiveness of drugs on health of patients ${ }^{18,19}$ This study showed favorable effects on progress of disease and health related quality of life as assessed by PASI ( $p$ value $=0.0001$ ) and DLQI ( $p$ value $=0.001$ ). PASI was decreased to $2.806 \pm$ 0.183 at end of study from $11.277 \pm 0.729$. Similarly DLQI was reduced to $5.55 \pm 0.53$ from $20.2 \pm 1.16$. These findings were in line with study conducted by Kragballe K and Van de Kerkhof (2006), as they reported that Betamethasone showed marked improvement of psoriatic lesions. ${ }^{20}$

Similarly Thawornchaisit and Harncharoen revealed that topically applied Betanmethasone had favorable effects on psoriatic patient in term of magnificently improving the PASI score in plaque type psoriatic patient. ${ }^{21,22}$

Beside of improving primary parameters of Psoriasis (PASI, DLQI) in our study additional benefit of Topical Betamethasone was magnificently reduces the
hsCRP levels $(p=0.0001)$. As hsCRP is an important predictable marker for systemic inflammation. Hence Betamethasone would able to reducing the chances of systemic consequences of Psoriasis. These findings were in agreement with the study conducted by Philippine Dermatological Society. They evaluated and compared the effects of Topical Betamethasone with Placebo and Atorvastatin (40mg) in psoriatic patients. They concluded that Topical Betamethasone as effective as Atorvastatin in reducing the hsCRP levels. ${ }^{23}$

In our study Topical Betamethasone usage showed better tolerability as patients did not manifest any severe adverse effect apart from those only $16.67 \%$ patient revealed minor skin manifestations. These findings were in line with study conducted by Afifi et al. (2005). As they showed that among all available topical therapeutic options for psoriasis, topical steroids were safe and effective option. ${ }^{24}$

This study supported that topical steroids would be best option for mild to moderate psoriasis with better tolerability as in line with Ahmad et al. (2013). ${ }^{25}$ As per guideline for psoriasis recommended by USA Topical Betamethasone effective as first line treatment option of all stages of psoriasis either as sole or combinatory therapy. ${ }^{26}$

\section{CONCLUSION}

This study result showed that Topical Betamethasone Valerate $0.1 \%$ amends the immune function and hampers the inflammatory process of disease to reduce it progress and enhanced quality of life in chronic plaque type psoriatic patients

\section{CONFLICT OF INTEREST}

No Conflict of interest 


\section{Copyright@ 22 Jan, 2019.}

\section{REFERENCES}

1. Menter A, Korman NJ, Elmets CA, Feldman SR, Gelf and JM, Gordon KB, Gottlieb A, Koo JY, Lebwohl M, Lim HW, Van Voorhees AS, Beutner $\mathrm{KR}$, Bhushan R. (2009). Guidelines of care for the management of psoriasis and psoriatic arthritis. Section 3.J Am Acad Dermatol, 60, 4, 643-59.

2. AsadF, Khan M, Rizvi F. Atorvastatin as an adjuvant with betamethasone vale rate reduces disease severity and cardiovascular risks in Psoriasis. Pak J Med Sci. 2017; 33(6):1507-11.

3. Ashcroft DM, Li Wan Po A, Griffiths CE. 2000. Therapeutic strategies for psoriasis. J Clin Pharm Ther, 25:2-10.

4. Peeters P, Ortonne JP, Sitbon R, et al. 2005. Cost-effectiveness of once-daily treatment with calcipotriol/betamethasonedipropionate followed by calcipotriol alone compared with tacalcitolin the treatment of Psoriasis vulgaris. Dermatology, 211:139-45.

5. Fenton C, Plosker G. 2004. Calcipotriol/Betamethasone dipropionate: A review. Am J Clin Dermatol, 5:463-78

6. Beato M. 1989. Gene regulation by steroid hormones. Cell, 56:33544.

7. De Jong EM, Ferrier CM, de Zwart A, et al. 1995. Effects of topical treatment with budesonide on parameters for epidermal proliferation, keratinization and inflammation in psoriasis. J Dermatol Sci, 9:185-94.

8. Vissers $W H$, Berends $M$, Muys $L$, et al. 2004. The effect of the combination of calcipotriol and betamethasonedipropionate versus both monotherapies on epidermal proliferation, keratinization and T-cell subset in chronic plaque psoriasis. Exp Dermatol, 13:106-12.

9. April W. Armstrong, Kory Parsi, Clayton W. Schupp, Philip J. MeaseKristina C. Duffin. Standardizing training for psoriasis measures: Effectiveness of an online training video on psoriasis area and severity index. JAMA Dermatol. 2013; 149(5):577-82.

10. Abou-Raya A and Abou-Raya S. Inflammation: A pivotal link between autoimmune diseases and atherosclerosis. Autoimmunity Rev 2006; 20:1-30.

11. Jain IVK and Lal H. C-reactive protein and uric acid levels in patients with psoriasis. Ind J ClinBiochem 2011; 26(3):309-11.

12. Feldman $S$ and Krueger $G$. Psoriasis assessment tools in clinical trials. Ann Rheum Dis. 2005 Mar; 64(Suppl 2): ii65-ii68.

13. Husain TM and Kim DH. C-reactive protein and erythrocyte sedimentation rate in orthopaedics. The Univ of Pennsylvania. Ortho J 2002; 15:13-16.
14. Finlay AY and Khan GK. Dermatology life quality index (DLQI): A simple practical measure for routine clinical use. Clin Exp Dermatol. 1994; 19:210-6.

15. Roeder A, Schaller M, Schafer-Korting M and Korting HC. Safety and efficacy of fluticasone propionate in the topical treatment of skin diseases. Skin Pharmacol Physiol 2005; 18:3-11.

16. Shephered A, Taheri A and Feldman R S. Once daily topical treatment for psoriasis: Calcipotriene+Betamethasone one two - compound topical formulation. Clin Cosmet Investig Dermatol. 2014; 7:19-22.

17. Dilnawaz M, Sadiq S, Shaikh ZI, Aziz H, Khan S, Jawad B. Clinical audit: Baseline psoriasis area and severityindex (PASI) and dermatology life quality index (DLQI) assessment of psoriasis patients. J Pak Assoc Dermatologists.2013; 23(4):407-11.

18. Lin $T$, See L, Shen $Y$, Liang $C$, Chang $H$ and Lin $Y$. Quality of life in patients with Psoriasis in Northern Taiwan. Chang Gung Med J 2011; 34:186-96.

19. Al Raddadi A, Jfri A, Samarghandi S, Matury N, Habibullah T, Alfarshoti $M$ and Mahdi A. Psoriasis: Correlation between severity index (PASI) and quality of life index (DLQI) based on the type of treatment. J Dermatol Dermatologic Surg 2016; 20(1):15-18.

20. Kragballe K, van de Kerkhof PC. 2006. Consistency of data in six phase III clinical studies of a two-compound product containing calcipotriol and betamethasone dipropionate ointment for the treatment of psoriasis. J Eur Acad Dermatol Venereol, 20:39-44.

21. Thawornchaisit $P$ and Harncharoen $K$. A comparative study of Tar and Betamethasone valerate in chronic plaque Psoriasis: A study in Thailand. J Med Assoc Thai 2007; 90(10):1997-2002.

22. Mattei $\mathrm{PL}$, Corey $\mathrm{KC}$ and Kimball $\mathrm{AB}$. Psoriasis area severity index (PASI) and the dermatology life quality index (DLQI): The correlation between disease severity and psychological burden in patients treated with biological therapies. J Eur Acad Dermatol Venereol 2014; 28(3):333-7.

23. Philippine dermatological society. Efficacy of atorvastatin as adjunctive treatment for chronic plaque type Psoriasis. Updated on 2015; https:// clinicaltrials.gov/ct2/ show/ NCT02432040.

24. Afifi T, de Gannes G, Huang C and Zhou Y. Topical therapies for psoriasis: Evidence based review. Can Fam Physician2005; 51:51925.

25. Ahmad GKA, Choudhary AM, Kondker L and Khan MSI. Comparative safety of topical calcipotriol $(0.005 \%)$ versus topical Corticosteroid (Betamethasone $\mathbf{0 . 1 \%}$ ) in plaque type psoriasis. J Pak Assoc Dermatologists 2013; 23(4):394-400.

26. Uva L, Miguel D, Pinheiro C, Antunes J, Cruz D, Ferreira $\mathrm{J}$ and Filipe $\mathrm{P}$ Mechanisms of action of topical corticosteroids in psoriasis. Intern J Endocrinol 2012; 2012: 1-16.

\section{AUTHORSHIP AND CONTRIBUTION DECLARATION}

\begin{tabular}{|c|c|c|c|}
\hline Sr. \# & Author-s Full Name & Contribution to the paper & Author $=$ s Signature \\
\hline 1 & Farah Asad & $\begin{array}{l}\text { Wrote the paper, Data collection } \\
\text { and data analyzed, Substantial } \\
\text { contributions to the conception or } \\
\text { design of the work and interpretation } \\
\text { of Data for the work. }\end{array}$ & \\
\hline 2 & Fatima Rizvi & $\begin{array}{l}\text { Drafting the work or revising it } \\
\text { critically for important Intellectual } \\
\text { content. } \\
\text { Review the literature. }\end{array}$ & \\
\hline
\end{tabular}

